\title{
Species richness and phylogenetic structure in plant communities: 20 years of succession
}

\author{
Jutta Stadler $^{1}$, Stefan Klotz ${ }^{1}$, Roland Brandl ${ }^{2}$, and Sonja Knapp ${ }^{1}$ \\ ${ }^{1}$ Helmholtz-Centre for Environmental Research, Department Community Ecology, Theodor-Lieser-Str. 4, \\ 06120 Halle/Saale, Germany \\ ${ }^{2}$ Philipps-University Marburg, Faculty of Biology, Department of Ecology, Animal Ecology, \\ 35032 Marburg, Germany \\ Correspondence to: Jutta Stadler (jutta.stadler@ufz.de)
}

Received: 20 April 2017 - Revised: 29 June 2017 - Accepted: 30 June 2017 - Published: 15 August 2017

\begin{abstract}
Secondary succession on arable fields is a popular system for studying processes influencing community assembly of plants. During early succession, the arrival and establishment of those propagules that can pass the environmental filters operating at a given site should be among the dominant processes leading to an initial increase in species richness. With ongoing succession, environmental filtering should decrease in relative importance compared to competitive interactions, which then should decrease species richness. Thereby, the phylogenetic structure of communities should change from random or clustered patterns during early succession to overdispersion. Disturbance is supposed to act as an additional filter, causing communities to be phylogenetically clustered. By analysing the species richness and phylogenetic structure of secondary succession in two different regions in Germany with three different disturbance levels each, we tested this general model. Although in one of the regions (Gimritz) we found the expected trajectory of species richness, phylogenetic structure did not follow the expected trend from random or clustered towards overdispersed communities. In the other region (Bayreuth), species richness did not follow the expected trajectory and phylogenetic structure remained clustered over the course of succession. A preliminary analysis of autecological characteristics of the species involved (Ellenberg indicator values) nevertheless showed clear contrasting trends. The idiosyncrasies of successional trajectories across sites might be due to the environmental context, the regional species pool as well as the legacy of former land use reflected in the seed bank.
\end{abstract}

\section{Introduction}

Observational studies are still important for understanding or at least inferring the processes that structure assemblages of species. Particularly at large spatial and temporal scales, observations are almost the only way for inferring processes that structure communities. Thereby, the study of environmental gradients is a useful approach. Gradients may range from large-scale gradients across latitude or elevation to small-scale gradients across borders of ecosystems (e.g. gradients of water availability or salinity; Whittaker, 1975). Thereby the assumption is always that the importance of processes changes in some way across the investigated gradient (e.g. from environmental filtering at unfavourable conditions to competition at favourable conditions; e.g. Petrů et al., 2006). A temporal gradient for which we expect changes in the importance of processes shaping species assemblages is succession. Particularly in plant ecology, numerous studies showed successional changes in species richness as well as community composition (e.g. Grime, 1979; Debussche et al., 1996; Prévosto et al., 2011; Knapp et al., 2016). At the beginning of a succession, the most important process structuring communities is the arrival of propagules from outside as well as the germination from the soil seed bank. Therefore, both random processes (arrival) as well as environmental filtering (conditions for germination) are expected to dominate community assembly during the early stages of succession (Cavender-Bares et al., 2009; Meiners et al., 2015). As succession proceeds, interspecific competition is expected to increase in importance (e.g. Dinnage, 2009). 
Species richness is probably the most widely used measure to quantify biodiversity across environmental gradients as well as along successional trajectories. Based on the successive arrival of propagules, one expects an increase of species richness during the early phase of succession. As soon as competition increases in importance, local extinctions of species might occur, leading to a decrease of species richness. Therefore, many reviews of succession and textbooks expect a peak of species richness in mid-successional assemblages of plants or animals (e.g. Smith and Smith, 2012), although patterns might be more complex (e.g. Prévosto et al., 2011). However, by restricting the measurement of biodiversity to species richness, one ignores almost $90 \%$ of the "overall diversity" (Lyashevska and Farnsworth, 2012). Measures of phylodiversity represent the amount of evolutionary history contained within species assemblages (Laity et al., 2015). Phylodiversity was identified as an important driver of ecosystem stability (Cadotte et al., 2012) and has been suggested as criterion of choice for the designation of protected areas (Vane-Wright et al., 1991; but see Winter et al., 2013).

Based on several assumptions, the phylodiversity of species assemblages also provides insights into processes of community assembly (Graham et al., 2009; Verdú et al., 2012; Meiners et al., 2015). Assuming that phylogenetic relatedness is a proxy for ecological relatedness (but see Gerhold et al., 2015; Lososová et al., 2016), the comparison of the phylodiversity of real assemblages with randomly constructed assemblages allows the relative importance of ecological processes to be inferred. Competition should lead to the coexistence of species with ecological differences. Therefore, the phylodiversity of real communities should be larger than expected by chance, which is also called "overdispersion" (but see Bennett et al., 2013). In contrast, in habitats with harsh ecological conditions where competition plays no role, we expect that species with similar traits coexist (ecological filtering; Cadotte and Tucker, 2017). Assuming that the similarity of traits is at least in part mapped by phylogenetic relatedness, this should lead to a phylodiversity lower than expected by chance (also called clustering; for critical comments see again Gerhold et al., 2015). In the context of the simple idea that at the beginning of the succession the arrival of propagules is important, we expect a clustered or random structure of phylogenetic diversity and with the increasing importance of competition a trend towards overdispersion (e.g. Purschke et al., 2013).

Land-use and its changes also affect the phylogenetic structure of assemblages. Agricultural intensification, for example, was shown to reduce the phylodiversity of birds (Frishkoff et al., 2014). The phylodiversity of plants declines with increasing mowing frequency in alpine grasslands (Mauchamp et al., 2014). These studies as well as studies on urbanization (e.g. Knapp et al., 2017) suggest that metrics of phylodiversity decrease with increasing land-use intensity. Few studies, however, assessed the effects of different types of land use on phylodiversity (e.g. searching Web of
Science (22 March 2016) for the topic mowing AND "phylogenetic diversity" resulted in two hits only: Dengler et al., 2014; Mauchamp et al., 2014).

We analysed the trajectories of plant assemblages following the abandonment of agricultural land use with respect to species richness and phylogenetic structure. According to the hypothesized processes described above, we predicted the following:

1. Disturbances like mowing or mulching lead to a reduction in species richness and to phylogenetic clustering.

2. In the course of succession, phylogenetic structure develops from a clustered or random pattern to overdispersion.

\section{Material and methods}

\subsection{Study sites}

The two study sites are located on former agricultural farmland situated in two regions, the "Mitteldeutsches Tiefland" (Gimritz) in central Germany and "Südostdeutsches Hügelland" (Bayreuth) in south-eastern Germany. The sites are both located in intensively used agricultural landscapes dominated by crop and meadow farming. On the two sites agricultural land use was abandoned in spring 1993 (Gimritz) and 1994 (Bayreuth; see Table 1).

The site at Gimritz is embedded between porphyritic hillsides and consists of shallow soils with little water retention capacity. Annual precipitation is low, because Gimritz is located in the rain shadow of the Harz mountains. Today, the site is adjacent to a small conservation area with semi-dry and dry grassland vegetation as well as to intensively used agricultural farmland (see also Stadler et al., 2006). Parts of the area are irregularly grazed by sheep. The sites were not fenced; but the shepherd made all efforts to keep the sheep out of the experimental site. The site in Bayreuth had been intensively used as farmland but was restored as a more natural area in 1993 with a number of newly created ponds and meadows. In the nearby surroundings, traditional crop farming as well as small woodland areas exist.

In spring of the year of abandonment an area of $40 \mathrm{~m} \times 100 \mathrm{~m}$ was ploughed at each of the two sites and harrowed to initiate succession. Within this area, three plots of $40 \mathrm{~m} \times 10 \mathrm{~m}$ were randomly assigned to one of the three treatments (control, mulching, mowing). Within each plot we permanently marked subplots of $2 \mathrm{~m} \times 2 \mathrm{~m}$ (10 subplots within each plot in Gimritz and 25 subplots within each plot in Bayreuth). Subsequently, plots were treated according to how they were assigned to the experimental manipulations in late summer as follows: (1) the plots assigned to the treatment "mowing" were mowed using a sickle bar mower with a mowing height of $10 \mathrm{~cm}$ and the mowed material was removed; (2) the plots assigned to the treatment "mulching" 
Table 1. Characteristics of the study sites Gimritz and Bayreuth: geographic coordinates, elevation above sea level, mean annual temperature (temp.), mean annual precipitation, year when the succession started, surrounding habitat and soil type according to the IUSS Working Group WRB (2007). All fields had been abandoned in spring.

\begin{tabular}{|c|c|c|c|c|c|c|c|}
\hline Site & $\begin{array}{l}\text { Geographical } \\
\text { coordinates }\end{array}$ & $\begin{array}{r}\text { Elevation } \\
{[\mathrm{m}]}\end{array}$ & $\begin{array}{l}\text { Temp. } \\
{\left[{ }^{\circ} \mathrm{C}\right]}\end{array}$ & $\begin{array}{r}\text { Precipitation } \\
{[\mathrm{mm}]}\end{array}$ & $\begin{array}{r}\text { Start of } \\
\text { succession }\end{array}$ & $\begin{array}{l}\text { Surrounding } \\
\text { habitat }\end{array}$ & $\begin{array}{l}\text { Soil } \\
\text { type }\end{array}$ \\
\hline Gimritz & $\mathrm{N} 51^{\circ} 33^{\prime} \mathrm{E} 11^{\circ} 50^{\prime}$ & 110 & 9.1 & 490 & 1993 & $\begin{array}{l}\text { Arable fields, meadows, } \\
\text { semi-dry and dry grasslands }\end{array}$ & $\begin{array}{l}\text { Mosaic of rankers } \\
\text { and brown soil }\end{array}$ \\
\hline Bayreuth & $\mathrm{N} 49^{\circ} 55^{\prime} \mathrm{E} 11^{\circ} 35^{\prime}$ & 355 & 8.2 & 720 & 1994 & Meadows; arable fields & $\begin{array}{l}\text { Stagnic gleysol } \\
\text { on sandstone }\end{array}$ \\
\hline
\end{tabular}

were mowed and the mowed material was distributed evenly over the respective plot; (3) the plots which served as a control received no treatment at all. Starting in the year of abandonment, cover/abundance of vascular plant species were recorded annually during the main vegetation period on each subplot according to the Braun-Blanquet scale (for a list of the common species recorded in Gimritz and Bayreuth see Appendix). Other plant groups like bryophytes were of low importance (biomass $\ll 5 \%$ ) and therefore not recorded. The quadrat size used was a compromise between the appropriate scale for the analysis of ecological interactions between species and work load. We are aware that using $2 \mathrm{~m} \times 2 \mathrm{~m}$ quadrats for analysis may be too large to demonstrate weak competitive effects. For further analyses we transformed the Braun-Blanquet scale into a rank scale ( $r$ to $1 ;+$ to $2 ; 1$ to 3 and so on) as a measure characterizing the cover/abundance of single species. The data analysed here comprises the years 1993 to 2015 (Gimritz) and 1994 to 2015 (Bayreuth). We were not able to sample the vegetation in all treatments in Bayreuth (see Fig. 1). For example, in 2011 the plots were accidentally mowed before the vegetation was recorded.

\subsection{Analysis and statistical methods}

Note that in each region we have only one plot assigned to each treatment. Therefore, the subplots within these plots are pseudo-replications and formal statistical tests are questionable. Therefore, we report only simple comparisons of our selected metrics characterizing succession (e.g. paired $t$-tests of treatments using the means across subplots; Spearman rank correlations between mean values of the selected metrics across subplots) to highlight the most evident and robust temporal patterns.

We calculated mean species richness for plots across subplots of each treatment and year within the two regions. We plotted this mean of species richness versus time. Numerous metrics are available to calculate the phylodiversity of communities (Tucker et al., 2016). Here we used for each subplot two widely applied measures: mean pairwise distance (MPD) and mean nearest taxon distance (MNTD; Webb et al., 2002), both weighted by cover/abundance of the species recorded within the subplots. MPD and MNTD are measures of phylogenetic divergence (Tucker et al., 2016). MPD
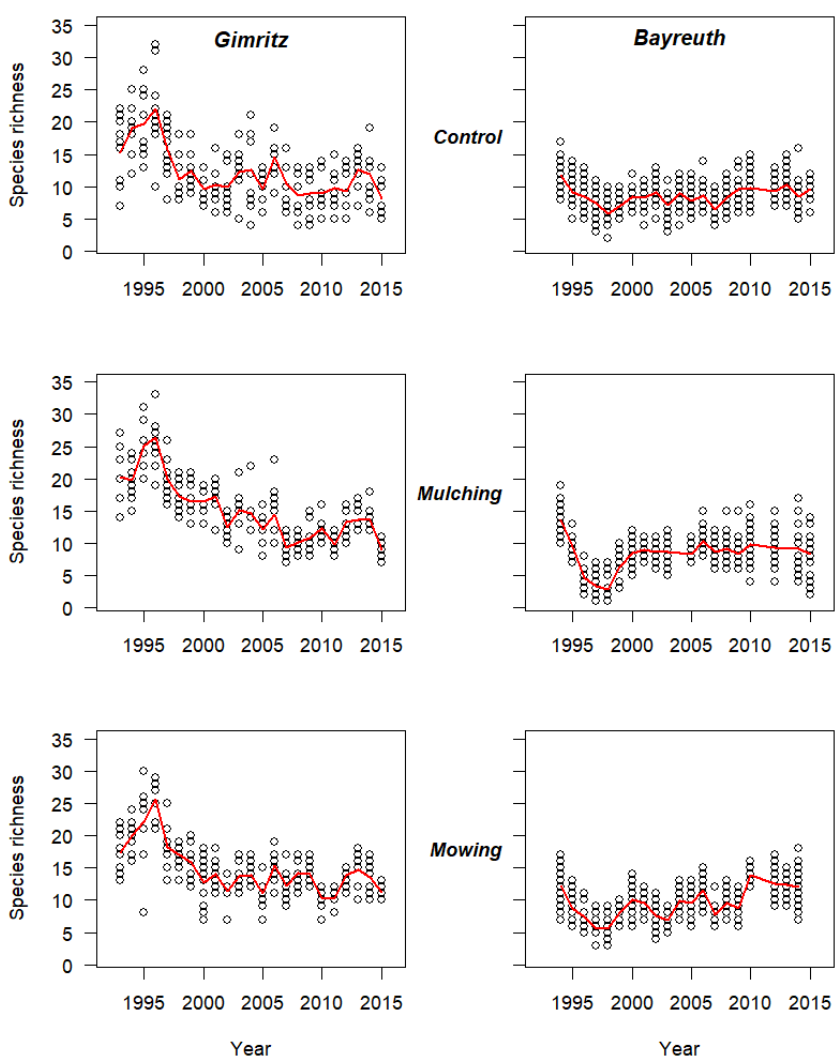

Figure 1. Species richness of subplots within each treatment plotted versus years for the study sites Gimritz and Bayreuth (see also Table 2). The red shows the mean across subplots.

is dominated by the deep phylogenetic relationships of the focal species assemblages; i.e. its calculation considers all pairwise distances within the community. MNTD considers the tips of a phylogenetic tree, i.e. only the shortest distances among species in an assemblage (Webb et al., 2002). Subsequently, we calculated the standardized effect sizes of MPD $\left(\mathrm{MPD}_{\text {ses }}\right)$ and MNTD $\left(\mathrm{MNTD}_{\text {ses }}\right)$ as [(observed metric - mean of expected metric) / standard deviation of expected metric], deriving expected mean and standard deviation from a null model. As a reasonable null model, we shuffled species names across the tips of the phylogeny 
(999 runs). This keeps the occurrence, cover/abundance as well as the recorded number of species within the subplots unchanged and therefore keeps the pattern of successional changes in species composition untouched. An effect size $>0$ (observed mean $>$ expected mean) indicates phylogenetic overdispersion, while an effect size $<0$ (observed mean $<$ expected mean) indicates clustering in comparison to the null model. Furthermore, assuming a standard normal distribution for the effect sizes, one can use the numeric value of the effect size to estimate the significance of individual values in comparison to the null model. Based on the standard normal distribution, we regard values $<-2$ and $>2$ as significant. We plot the effect sizes for each subplot versus time and, similarly to species richness, we calculated the means of $M P D_{\text {ses }}$ and $M N T D_{\text {ses }}$ for each treatment and year within regions for our simple statistical tests. The phylogeny of the occurring species was extracted from the data paper Daphne (Durka and Michalski, 2012 and 2016).

We are aware that phylodiversity might be a weak guide to the processes influencing plant assemblages (e.g. Lososová et al., 2016). Therefore, we supplement our analysis with the trajectories of the mean autecological characteristics of the species using Ellenberg values (Ellenberg et al., 1992). These values assign, to most of the species recorded during our study, rank values for their behaviour across ecological gradients. For the present study we used indicator values for soil productivity or fertility ( $N$-value; range from 1 [low fertility] and 9 [high fertility]), soil humidity ( $F$-value; range from 1 [dry] to 12 [water plants]), soil acidity ( $R$-value; range from 1 [acid soils] to 9 [calcareous soils]), and light availability ( $L$ value; range from 1 [shadow] to 9 [full sun light]). Similarly to the analysis of phylogenetic structure, we first calculated a value for each subplot (mean value across species recorded on that subplot) and for further analysis subsequently the mean cross subplots for each plot. A full analysis of the autecological traits is in preparation; therefore here we only document the mean values of the selected indicator values (note that this may lead to a bias; Zelený and Schaffers, 2012) For all calculations we used the appropriate functions in $\mathrm{R}(\mathrm{R}$ Core Team, 2014) provided by several add-on packages, in particular picante (Kembel et al., 2010).

\section{Results and discussion}

\subsection{Species richness}

Mean species richness across all years and subplots varied across the three treatments between 12 and 15 in Gimritz (control: 12; mulching: 15; mowing: 15) and between 10 and 8 in Bayreuth (control: 10, mulching: 8; mowing: 9). Thus, Gimritz was more species rich than Bayreuth (Fig. 1). For a comparison of the treatments we paired the mean values of each year for Gimritz as well as Bayreuth. In Gimritz, differences in species richness were significant using a paired $t$ test (difference control - mulching $=-2.9$ species; $p<0.05$;
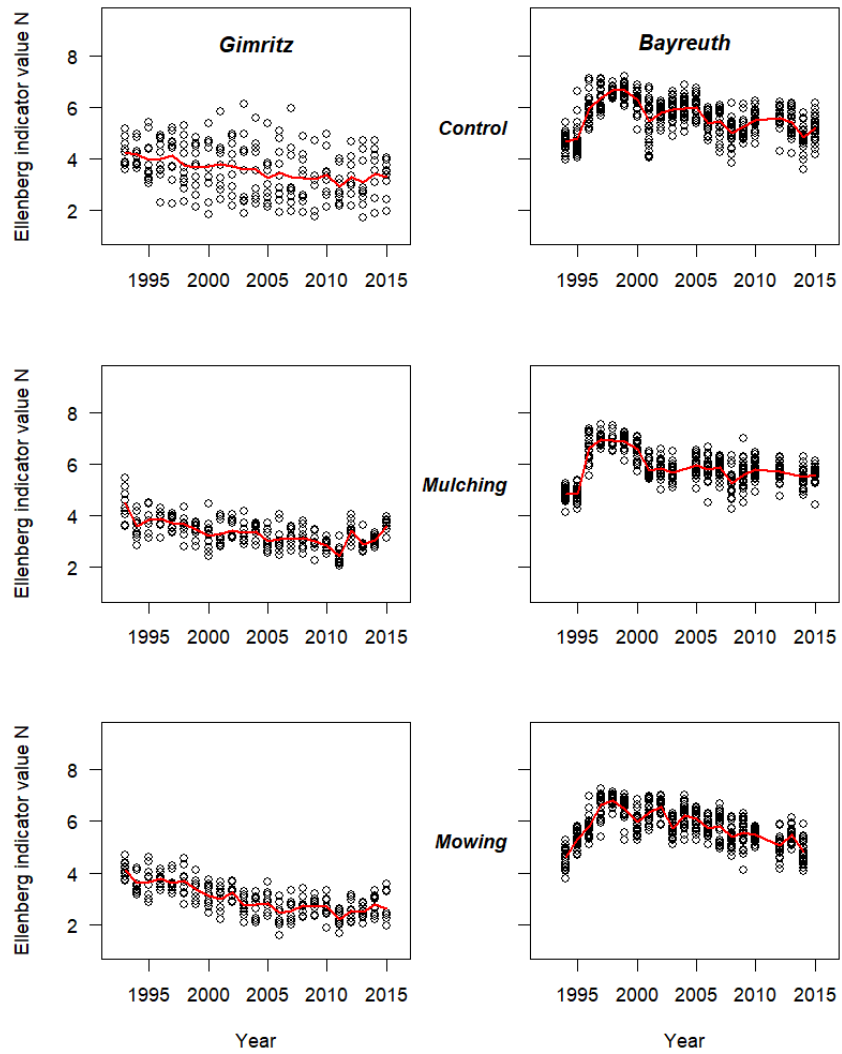

Figure 2. Mean indicator value for soil fertility ( $N$-value) of subplots within each treatment plotted versus years for the study sites Gimritz and Bayreuth (see also Table 3). The red shows the mean across subplots.

difference control - mowing $=-2.6$ species; $p<0.05)$. In Bayreuth, these differences were not significant. Thus, in Gimritz, disturbances increased species richness whereas in Bayreuth, disturbances had no effect.

Within regions, the trajectories of species richness with proceeding succession were consistent (rank correlations between $r=0.7$ and $r=0.91 ; p<0.05$ in all cases). The general pattern of the trajectories of species richness, however, differed between the two regions. Correlating the mean species richness for each treatment and year since the start of the succession between the two regions, the rank correlations were even negative (control: $r=-0.41$; mulching: $r=-0.38$; mowing: $r=-0.45$ ). In Gimritz, species richness increased during the first 3 years and decreased afterwards (see also Stadler et al., 2006), showing the expected hump of species richness. Across all years there was a general negative trend for all three treatments (Table 2). In Bayreuth, species richness decreased during the first 5 years and increased afterwards, but the overall trend as measured by the rank correlation coefficient of the mean values versus time was not consistent for the three treatments.

We found few regularities in the successional trajectories of species richness between the two regions. The only clear 
Table 2. Spearman rank correlations of the metrics species richness, effect size of mean pairwise phylogenetic distance $\left(\mathrm{MPD}_{\mathrm{ses}}\right)$ as well as effect size of mean nearest taxon distance $\left(\mathrm{MNTD}_{\mathrm{ses}}\right)$ versus years since start of the succession. For each year and region, we used the mean of the metrics across subplots. Significant values $(p<0.05)$ are in bold. Note that because of the temporal autocorrelation these significance values are not strictly valid. For mean $\mathrm{MPD}_{\text {ses }}$ and $\mathrm{MNTD}_{\text {ses }}$ we also give the number of years in which the mean values were smaller than 0 , therefore indicating that the species co-occurring within subplots are phylogenetically more related than expected by chance ( $=$ clustered). If species composition is random in respect to phylogenetic relatedness we would expect that half of the mean values are $<0$ and half of the values $>0$. In our case all values were $<0$. Using the binomial distribution such a result is significant.

\begin{tabular}{|c|c|c|c|c|}
\hline Metric & Region & Control & Mulching & Mowing \\
\hline species rich & Gim & -0.67 & -0.84 & -0.68 \\
\hline MPD $_{\text {ses }}$ & & 0.25 & -0.09 & -0.59 \\
\hline Number of years $\mathrm{MPD}_{\text {ses }}<0$ & & $13(56 \%)$ & $21(84 \%)$ & $23(100 \%)$ \\
\hline MNT & & -0.65 & -0.78 & -0.59 \\
\hline Number & & $(100 \%)$ & $3(100 \%)$ & $(100 \%)$ \\
\hline species ri & Bayreuth & -0.31 & 0.19 & 0.54 \\
\hline MPD $_{\text {ses }}$ & & -0.04 & -0.46 & -0.53 \\
\hline Number & & 18 & 17 & 17 \\
\hline MNTD & & 0.41 & -0.16 & 0.66 \\
\hline Number of years MNTD $_{\text {ses }}<0$ & & $21(100 \%)$ & $19(100 \%)$ & $20(100 \%)$ \\
\hline
\end{tabular}

pattern was that species richness was higher in Gimritz compared to Bayreuth and that the successional trajectories were consistent across treatments within each region. An important factor controlling species richness as well as secondary succession is soil fertility (Wright and Fridley, 2010). In the area of Bayreuth, the soils are comparatively nutrient rich compared to the soils in Gimritz, which is also clearly shown by the Ellenberg indicator values for soil fertility (Fig. 2). At fertile conditions, one expects that fast-growing species dominate the vegetation, leading to a reduction of species richness. This would - at least in part - explain the clear decrease of species richness during the first years of succession in Bayreuth. In contrast, at low nutrient levels (like in Gimritz), early successional species with low competitive ability are able to colonize the plots during the initial phase of succession. The low nutrient levels decelerate the establishment of competitive species so that early successional species can persist for a longer time, leading to the observed initial increase of species richness in Gimritz.

The indicator values for soil fertility (Ellenberg indicator value $N$; Fig. 2) have low values in Gimritz and higher values in Bayreuth. Interestingly, in Gimritz the mean $N$-values of co-occurring species decreased with time (decreasing soil fertility; Table 3) whereas in Bayreuth the values showed a more complex pattern with a peak after 4 to 5 years (Fig. 2). First of all, these changes in the indicator values show that we have a clear succession in cover/abundance of species that differ in autecological traits in both regions. However, the succession again follows different trajectories. The inspection of the temporal trends of the other values underlines this conclusion (Fig. 3; Table 3). At present we are not able to offer a convincing explanation for these complex differences between regions and we hope to obtain more clear-cut con-
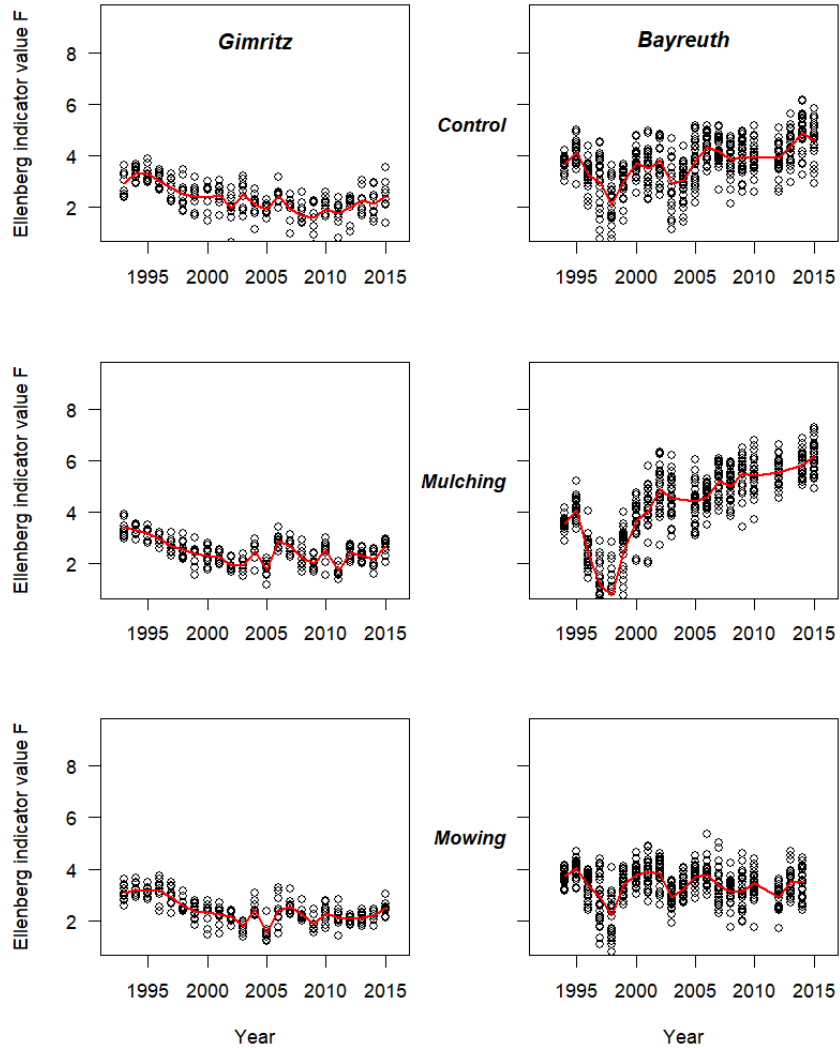

Figure 3. Mean indicator value for soil moisture ( $F$-value) of subplots within each treatment plotted versus years for the study sites Gimritz and Bayreuth (see also Table 3). The red shows the mean across subplots. 
Table 3. Spearman rank correlations of the mean indicator values across years for Gimritz and Bayreuth. For each year and region, we used the mean of the indicator values across subplots. Significant values $(p<0.05)$ in bold. Note that because of the temporal autocorrelation these significance values are not strictly valid.

\begin{tabular}{lllrrr}
\hline Metric & & Region & Control & Mulching & Mowing \\
\hline Soil fertility & N & Gimritz & $\mathbf{- 0 . 8 8}$ & $\mathbf{- 0 . 7 1}$ & $\mathbf{- 0 . 8 6}$ \\
Soil moisture & F & & $-\mathbf{0 . 7 1}$ & $-\mathbf{0 . 5 0}$ & $-\mathbf{0 . 6 3}$ \\
Soil acidity & R & & $\mathbf{0 . 5 7}$ & 0.23 & $\mathbf{0 . 6 6}$ \\
Light availability & L & & $-\mathbf{0 . 6 9}$ & $-\mathbf{0 . 7 7}$ & $-\mathbf{0 . 6 3}$ \\
& N & Bayreuth & -0.34 & -0.31 & -0.38 \\
& F & & $\mathbf{0 . 7 0}$ & $\mathbf{0 . 9 2}$ & -0.16 \\
& R & & 0.19 & 0.35 & 0.086 \\
& L & & $-\mathbf{0 . 7 8}$ & $\mathbf{- 0 . 7 9}$ & $\mathbf{- 0 . 6 5}$ \\
\hline
\end{tabular}

clusions with detailed analysis of species turnover (in preparation).

We expected that disturbances (in our case "mulching" and "mowing") decrease species richness of plant assemblages. In contrast, we found no effect or even a positive effect of these treatments on the species richness within the two regions (Fig. 1). Again the nutrient level may hold one key. At high nutrient levels the species may be able to compensate for the removal of biomass. However, the finding that disturbances increase species richness in Gimritz contradicts the idea that the recruitment of competitive species is slower under nutrient-poor conditions. However the species pool may also play an important role because it determines which species are available for the assembly of the communities and the traits of species determine the competitive hierarchies and thereby also species richness.

Another potential explanation for the effects of disturbances invokes the seed bank. The seed bank echoes former land use at the sites as well as the regional species pool. Therefore, secondary succession is not only structured by species arriving in an area but also by land-use legacies (e.g. Johnson et al., 2015). Given these influences, successional trajectories of species are idiosyncratic. Furthermore, species richness is a metric that is not able to capture the processes influencing the assembly of communities. Therefore, we explored the possibilities offered by analysing the phylogenetic structure to understand secondary succession.

\subsection{Phylogenetic structure}

Although most $\mathrm{MPD}_{\mathrm{ses}^{-}}$and $\mathrm{MNTD}_{\text {ses-values fall between }}$ -2 and 2, there was a tendency of MPD $\mathrm{Mes}_{\text {ses }}$ to be lower than expected by chance (Table 2, Figs. 4, 5). Following common assumptions, this suggests that environmental filtering rather than competition is important. However, the level of clustering and overdispersion depends on the species pool used for constructing the phylogeny and the null model. We used the species recorded during the 20 years on the plots. Using a broader species pool would certainly lead to even higher levels of clustering. Furthermore, the differences in the species
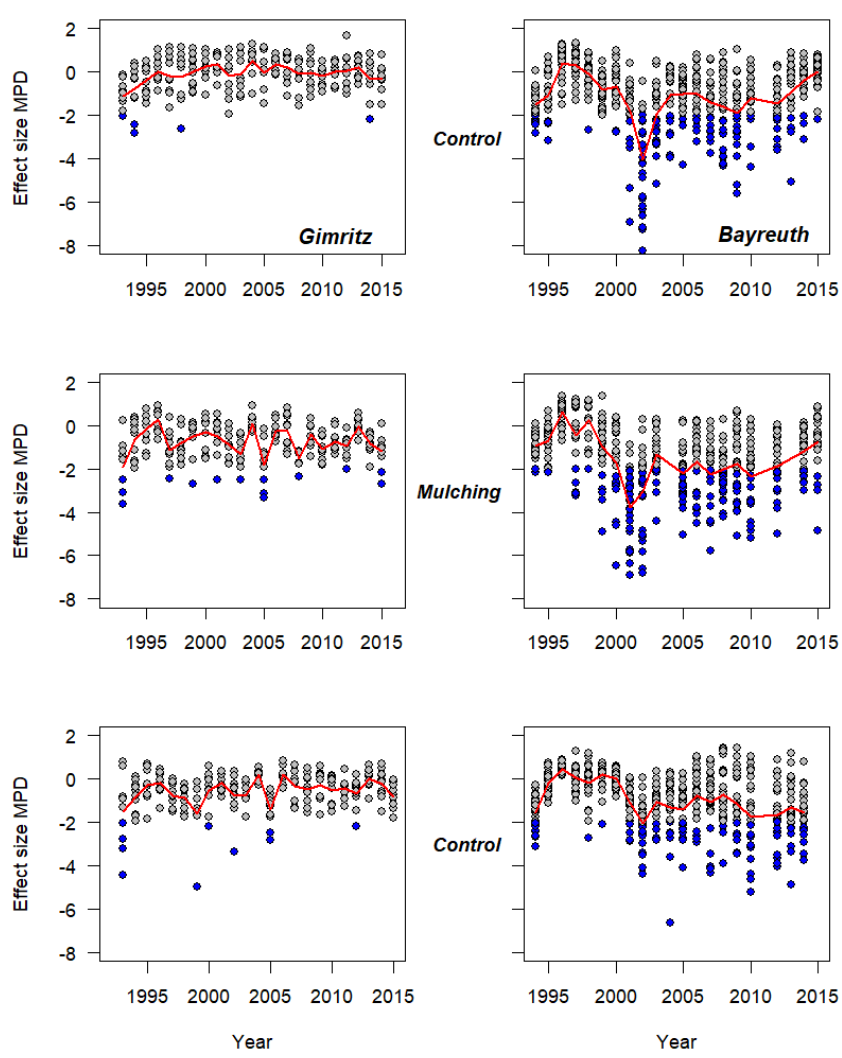

Figure 4. Trajectory of the effect sizes of the mean pairwise phylogenetic distances (MPD) of plant communities within subplots for each treatment in Gimritz and Bayreuth. For details about calculating the effect sizes see Material and Methods. Symbols in blue indicate significant mean effect sizes. The red line gives the mean effect sizes of the metrics.

pool between the two regions do not allow the strength of clustering between the two regions to be compared.

Contrary to the expectation outlined within the introduction we found in both regions no increase of the MPD ${ }_{\text {ses }}$ as well as of MNTD $_{\text {ses }}$ with time (Table 2; Figs. 4, 5). In Gimritz, $\mathrm{MNTD}_{\text {ses }}$ even showed a tendency to decrease with time. 

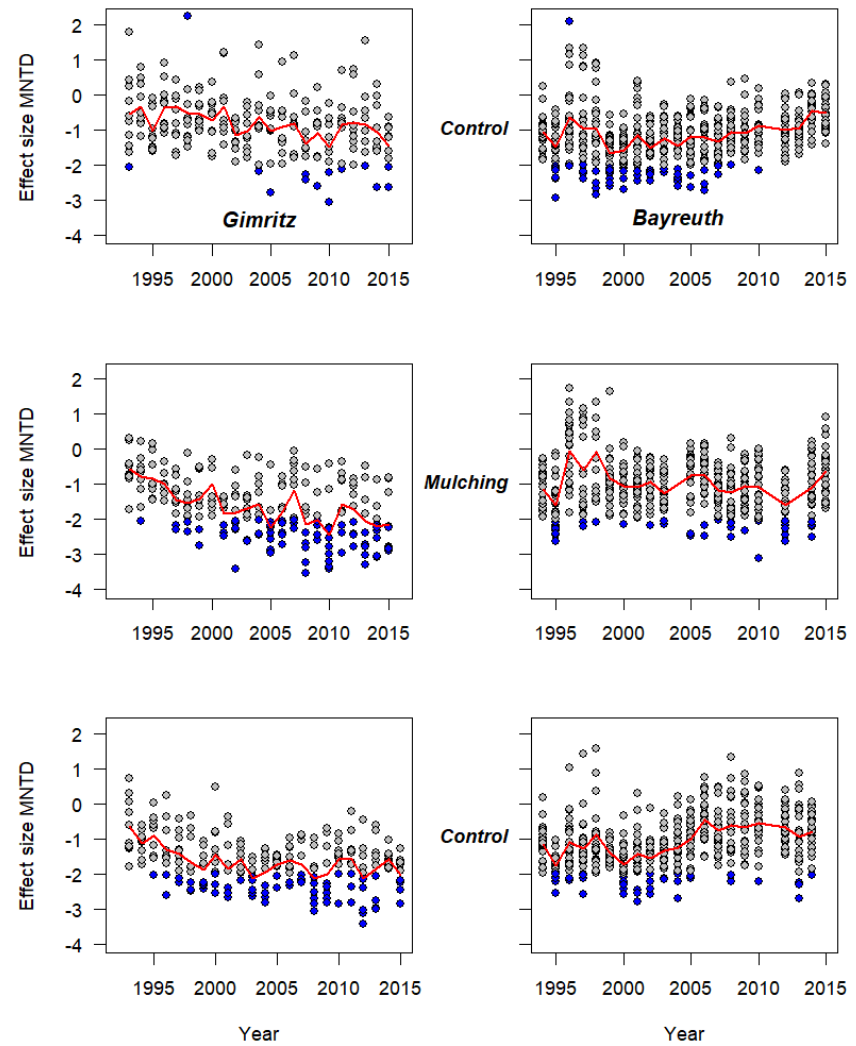

Figure 5. Trajectory of the effect sizes of the mean phylogenetic mean nearest taxon distances (MNTD) of plant communities within subplots for each treatment in Gimritz and Bayreuth. For details on calculating the effect sizes see Material and Methods. Symbols in blue indicate significant mean effect sizes. The red line gives the mean effect sizes of the metrics.

Furthermore, a visual inspection of Figs. 4 and 5 revealed also no striking differences between the three treatments. Meiners et al. (2015) suggested that the phylogenetic structure of a community develops from a random or clustered pattern at the start of succession to an overdispersed structure with increasing competition during succession. Similarly, Dinnage (2009) showed that disturbance lead to clustered species communities in old field systems. In our case, phylogenetic structure was in most cases either random or clustered. Similarly, Čeplová et al. (2015) found that urban plant communities were phylogenetically clustered to a similar extent, independent of the level of disturbance. Overall, our results are not consistent with the mentioned predictions and the trends of phylogenetic structure were again idiosyncratic depending on region and treatment.
Overall, the inconsistent results suggest that secondary succession does not follow the simple model that during succession communities develop from assemblages structured by environmental filtering to assemblages structured by competition. In fact, one important assumption of our analysis is that phylogenetic relatedness reflects the similarity of traits important for competitive interactions. However, this is far from clear (see also Gerhold et al., 2015) and analyses of urban floras showed that phylodiversity is only a weak proxy of functional diversity (Lososová et al., 2016). This and the idiosyncratic legacies of the species pool lead to the inconsistent patterns found during our analysis. Even our preliminary analysis of the changes in the autecological characteristic of species suggests very different successional trajectories (Table 3). The different histories and climates of the two sites leave no degrees of freedom to explain these differences. The next step is to include more sites in our analyses. Furthermore, the comparison of the traits of species occurring in the surroundings with the species that succeed to colonize the plots might help to understand the successional pathways of secondary succession in more detail.

Data availability. Data are not available to the public as they are used for further analysis and further publications. Data are available on request. 


\section{Appendix A}

Table A1. List of the more common species (species that occurred in at least $5 \%$ of all subplots of one site) recorded across all subplots and years in Gimritz as well as in Bayreuth. Furthermore, we list for these species the mean of the recoded Braun-Blanquet values (see Material and methods) for the subplots. The species names follow Biolflor (http://www2.ufz.de/biolflor/index.jsp).

\begin{tabular}{|c|c|c|c|c|}
\hline \multirow[t]{2}{*}{ Species names } & \multirow{2}{*}{$\begin{array}{r}\text { Gimritz } \\
\text { cover/abundance }\end{array}$} & \multirow[b]{2}{*}{$\%$ subplots } & \multirow{2}{*}{$\begin{array}{r}\text { Bayreuth } \\
\text { cover/abundance }\end{array}$} & \multirow[b]{2}{*}{$\%$ subplots } \\
\hline & & & & \\
\hline Achillea setacea & 0.13 & 6.23 & & \\
\hline Agrostis capillaris & 1.98 & 53.26 & 0.51 & 15.67 \\
\hline Agrostis stolonifera & & & 0.24 & 8.87 \\
\hline Alopecurus pratensis & & & 1.07 & 26.87 \\
\hline Apera spica-venti & 0.51 & 18.99 & 0.16 & 8.53 \\
\hline Arabidopsis thaliana & 0.21 & 13.35 & & \\
\hline Arrhenatherum elatius & 2.69 & 70.92 & 1.21 & 34.4 \\
\hline Bromus sterilis & 0.38 & 15.13 & & \\
\hline Carduus acanthoides & 0.34 & 13.65 & & \\
\hline Carex hirta & & & 0.58 & 15.87 \\
\hline Carlina vulgaris & 0.07 & 5.64 & & \\
\hline Cerastium semidecandrum & 0.08 & 5.64 & & \\
\hline Cirsium arvense & 0.13 & 5.19 & 2.01 & 61.93 \\
\hline Cirsium vulgare & 0.15 & 7.12 & 0.39 & 17.13 \\
\hline Dactylis glomerata & 0.74 & 32.2 & 1.77 & 48.53 \\
\hline Elytrigia arenosa & 0.83 & 23.74 & 2.64 & 58.73 \\
\hline Epilobium tetragonum & 0.16 & 8.61 & 0.81 & 32.33 \\
\hline Eryngium campestre & 2.03 & 73.44 & & \\
\hline Erysimum crepidifolium & 0.7 & 28.04 & & \\
\hline Falcaria vulgaris & 1.52 & 58.16 & & \\
\hline Festuca laevigata & 0.15 & 5.19 & & \\
\hline Festuca ovina & 1.39 & 39.76 & & \\
\hline Festuca rubra & 0.22 & 9.35 & 0.38 & 13.47 \\
\hline Festuca rupicola & 2.44 & 64.24 & & \\
\hline Filipendula ulmaria & & & 0.48 & 11.47 \\
\hline Galium x pomeranicum & 1.99 & 57.12 & & \\
\hline Helictotrichon pratense & 0.12 & 5.34 & & \\
\hline Hieracium pilosella & 2.05 & 52.52 & & \\
\hline Juncus conglomeratus & & & 0.34 & 13.07 \\
\hline Juncus effusus & & & 0.14 & 5 \\
\hline Koeleria macrantha & 0.5 & 22.11 & & \\
\hline Lathyrus tuberosus & 0.28 & 11.28 & & \\
\hline Myosotis stricta & 0.16 & 10.09 & & \\
\hline Phleum pratense & & & 0.84 & 28.13 \\
\hline Picris hieracioides & 0.25 & 12.61 & & \\
\hline Plantago lanceolata & & & 0.32 & 11 \\
\hline Poa angustifolia & 0.85 & 25.37 & & \\
\hline Poa pratensis & 0.56 & 14.09 & 2.13 & 57.4 \\
\hline Polygonum aviculare & 0.15 & 10.24 & & \\
\hline Potentilla argentea & 0.08 & 5.49 & & \\
\hline Ranunculus repens & & & 0.14 & 5.47 \\
\hline Rosa canina & 0.22 & 9.64 & & \\
\hline Rubus idaeus & & & 0.16 & 5.13 \\
\hline Securigera varia & 0.21 & 7.86 & & \\
\hline Senecio vernalis & 0.32 & 15.88 & & \\
\hline Solidago canadensis & & & 0.53 & 14.73 \\
\hline Taraxacum officinale & 0.82 & 31.6 & 1.37 & 40.93 \\
\hline Tragopogon pratensis & 0.1 & 6.08 & & \\
\hline Trifolium arvense & 0.3 & 14.99 & & \\
\hline Tripleurospermum perforatum & 0.54 & 18.84 & 0.28 & 8.67 \\
\hline Valeriana officinalis & & & 0.42 & 13.8 \\
\hline Vicia hirsuta & 1.03 & 37.98 & 0.86 & 38.67 \\
\hline Vicia sativa & 0.28 & 15.13 & 0.24 & 11.87 \\
\hline Vicia tetrasperma & 0.41 & 19.29 & 0.2 & 11.67 \\
\hline Vulpia myuros & 1.18 & 29.67 & & \\
\hline
\end{tabular}


Competing interests. The authors declare that they have no conflict of interest.

Acknowledgements. We thank the landowners (Gimritz: Gneist \& Bender GbR Landwirtschaft; Bayreuth: LBV Lindenhof) for permission to use their land for such a long time. Alexander Harpke helped us to extract the species lists from our data bank.

Edited by: Daniel Montesinos

Reviewed by: two anonymous referees

\section{References}

Bennett, J. A., Lamb, E. G., Hall, J. C., Cardinal-Mc Teague, W. M., and Cahill, J. F.: Increased competition does not lead to increased phylogenetic overdispersion in a native grassland, Ecol. Lett., 16, 1168-1176, 2013.

Cadotte, M. W. and Tucker, C. M.: Should environmental filtering be abandoned?, Trends Ecol. Evol., 32, 429-437, 2017.

Cadotte, M. W., Dinnage, R., and Tilman, D.: Phylogenetic diversity promotes ecosystem stability, Ecology, 93, 223-233, 2012.

Cavender-Bares, J., Kozak, K. H., Fine, P. V., and Kembel, S. W.: The merging of community ecology and phylogenetic biology, Ecol. Lett., 12, 693-715, 2009.

Čeplová, N., Lososová, Z., Zelený, D., Chytrý, M., Danihelka, J., Fajmon, K., Láníková, D., Preislerová, Z., Řehořek, V., and Tichý, L.: Phylogenetic diversity of central-European urban plant communities: effects of alien species and habitat types, Preslia, 87, 1-16, 2015.

Debussche, M., Escarre, J., Lepart, J., Houssard, C., and Lavorel, S.: Changes in Mediterranean plant succession: Old-fields revisited, J. Veg. Sci., 7, 519-526, 1996.

Dengler, J., Janisova, M., Torok, P., and Wellstein, C.: Biodiversity of Palaearctic grasslands: a synthesis, Agr. Ecosyst. Environ., 182, 1-14, 2014.

Dinnage, R.: Disturbance alters the phylogenetic composition and structure of plant communities in an old field system, PLoS ONE, 4, e7071, https://doi.org/10.1371/journal.pone.0007071, 2009.

Durka, W. and Michalski, S.: Daphne: a dated phylogeny of a large European flora for phylogenetically informed ecological analyses, Ecology, 93, 2297, https://doi.org/10.1890/12-0743.1, 2012.

Durka, W. and Michalski, S.: Daphne: a dated phylogeny of a large European flora for phylogenetically informed ecological analyses, Figshare, Ecological Archives E093-214, https://doi.org/10.6084/m9.figshare.c.3305040.v1, 2016.

Ellenberg, H., Weber, H. E., Düll, R., Wirth, V., Werner, W., and Paulißen, D.: Zeigerwerte von Pflanzen in Mitteleuropa, Scr. Geobot., 18, 2. Auflage, Univ. Göttingen, 1992.

Frishkoff, L. O., Karp, D. S., M'Gonigle, L. K., Mendenhall, C. D., Zook, J., Kremen, C., Hadly, E. A., and Daily, G. C.: Loss of avian phylogenetic diversity in neotropical agricultural systems, Science, 345, 1343-1346, 2014.

Gerhold, P., Cahill, J. F., Winter, M., Bartish, I. V., and Prinzing, A.: Phylogenetic patterns are not proxies of community assembly mechanisms (they are far better), Funct. Ecol., 29, 600-614, 2015.
Graham, C. H., Parra, J. L., Rahbeck, C., and McGuire, J. A.: Phylogenetic structure in tropical hummingbird communities, P. Natl. Acad. Sci. USA, 106, 19673-19678, 2009.

Grime, J. P.: Plant Strategies and Vegetation Processes, John Wiley, Chichester, 1979.

IUSS Working Group WRB: World reference base for soil resources 2007, World Soil Resources Reports No. 103, FAO, Rome, first updated 2007.

Johnson, A. L., Tauzer, E. C., and Swan, C. M.: Human legacies differentially organize functional and phylogenetic diversity of urban herbaceous plant communities at multiple spatial scales, Appl. Veg. Sci., 18, 513-527, 2015.

Kembel, S. W., Cowan, P. D., Helmus, M. R., Cornwell, W. K., Morlon, H., Ackerly, D. D., Blomberg, S. P., and Webb, C. O.: Picante: R tools for integrating phylogenies and ecology, Bioinformatics, 26, 1463-1464, 2010.

Knapp, S., Stadler, J., Harpke, A., and Klotz, S.: Dispersal traits as indicators of vegetation dynamics in long-term old-field succession, Ecol. Indic., 65, 44-54, 2016.

Knapp, S., Winter, M., and Klotz, S.: Increasing species richness, but decreasing phylogenetic richness and divergence over a 320year period of urbanization, J. Appl. Ecol., 54, 1152-1160, 2017.

Laity, T., Laffan, S. W., González-Orozco, C. E., Faith, D. P., Rosauer, D. F., Byrne, M., Miller, J. T., Crayn, D., Costion, C., Moritz, C. C., and Newport, K.: Phylodiversity to inform conservation policy: An Australian example, Sci. Total Environ., 534, 131-143, 2015.

Lososová, Z., Čeplová, N., Chytrý, M., Tichý, L., Danihelka, J., Fajmon, K., Láníková, D., Preislerová, Z., and Řehořek, V.: Is phylogenetic diversity a good proxy for functional diversity of plant communities? A case study from urban habitats, J. Veg. Sci., 27, 1036-1046, 2016.

Lyashevska, O. and Farnsworth, K. D.: How many dimensions of biodiversity do we need?, Ecol. Indic., 18, 485-492, 2012.

Mauchamp, L., Mouly, A., Badot, P. M., and Gillet, F.: Impact of management type and intensity on multiple facets of grassland biodiversity in the French Jura Mountain, Appl. Veg. Sci., 17, 645-657, 2014.

Meiners, S. J., Cadotte, M. W., Fridley, J. D., Pickett, S. T., and Walker, L. R.: Is successional research nearing its climax? New approaches for understanding dynamic communities, Funct. Ecol., 29, 154-164, 2015.

Petrů, M., Tielbörger, K., Belkin, R., Sternberg, M., and Jeltsch, F.: Life history variation in an annual plant under two opposing environmental constraints along an aridity gradient, Ecography, 29, 66-74, 2006.

Prévosto, B., Kuiters, L., Bernhardt-Römermann, M., Dolle, M., Schmidt, W., Hoffmann, M., Van Uytvanck, J., Bohner, A., Kreiner, D., Stadler, J., Klotz, S., and Brandl, R.: Impacts of land abandonment on vegetation: Successional pathways in European habitats, Folia Geobot., 46, 303-325, 2011.

Purschke, O., Schmid, B. C., Sykes, M. T., Poschlod, P., Michalski, S. G., Durka, W., Kühn, I., Winter, M., and Prentice, H. C.: Contrasting changes in taxonomic, phylogenetic and functional diversity during a long-term succession: insights into assembly processes, J. Ecol., 101, 857-866, 2013.

$\mathrm{R}$ Core Team: R: A language and environment for statistical computing, in: R Foundation for Statistical Computing Vienna, Aus- 
tria, version 3.3.1, available at: http://www.R-project.org/ (last access: 21 June 2016), 2014.

Smith, T. M. and Smith, R. L.: Elements of Ecology, eight editions, Pearson, Boston, 2012.

Stadler, J., Trefflich, A., Brandl, R., and Klotz, S.: Spontaneous regeneration of dry grasslands on set-aside fields, Biodiv. Conserv., 16, 621-630, 2006.

Tucker, C. M., Cadotte, M. W., Carvalho, S. B., Davies, T. J., Ferrier, S., Fritz, S. A., Grenyer, R., Helmus, M. R., Jin, L. S., Mooers, A. O., Pavoine, S., Purschke, O., Redding, D. W., Rosauer, D. F., Winter, M., and Mazel, F.: A guide to phylogenetic metrics for conservation, community ecology and macroecology, Biol. Rev., 92, 698-715, 2016.

Vane-Wright, R. I., Humphries, C. J., and Williams, P. H.: What to protect?-Systematics and the agony of choice, Biol. Conserv., 55, 235-254, 1991.

Verdú, M., Gómez-Aparicio, L., and Valiente-Banuet, A.: Phylogenetic relatedness as a tool in restoration ecology: a meta-analysis, Proc. Roy. Soc. B., 279, 1761-1767, 2012.
Webb, C. O., Ackerly, D. D., McPeek, M. A., and Donoghue, M. J.: Phylogenies and community ecology, Annu. Rev. Ecol. Syst., 33, 475-505, 2002.

Whittaker, R. H.: Communities and Ecosystems, Macmillan, New York, 1975.

Winter, M., Devictor, V., and Schweiger, O.: Phylogenetic diversity and nature conservation: where are we?, Trends Ecol. Evol., 28, 199-204, 2013.

Wright, J. P. and Fridley, J. D.: Biogeographic synthesis of secondary succession rates in eastern North America, J. Biogeogr., 37, 1584-1596, 2010.

Zelený, D. and Schaffers, A. P.: Too good to be true: pitfalls of using mean Ellenberg indicator values in vegetation analyses, $\mathrm{J}$. Veg. Sci., 23, 419-431, 2012. 